\title{
SOURCES OF COMPETITIVE ADVANTAGES AND BUSINESS PERFORMANCE
}

\author{
Jesper Strandskov \\ Department of Management and International Business, The Aarhus School of Business, \\ Haslegaardsvej 10, DK-8210 Aarhus V, Denmark. \\ Tel.: + 458948 6648,Fax +45896 125,E-mail: jsv@.dk \\ Received 0603 2006; accepted 28042006
}

\begin{abstract}
Based on data from the European meat processing industry three sets of competitive sources on business performance are studied: Firm Specific Advantages (FSAs), Localizational Specific Advantages (LSAs) and Relation Specific Advantages (RSAs). The results indicate that the FSAs and the RSAs are the most important explanatory variables on business performance, however, with strong interaction effects between the two sets of variables. Given the findings, we call for further empirical validation of how the different sets of competitive advantages interact and reinforce each. A closer examination of the nature of the RSAs, ie resource accumulation and development through inter-firm co-operation is also needed.
\end{abstract}

Keywords: Sources of competitive advantages, business performance, confirmative factor analysis, structural equation modelling.

\section{Introduction}

For years, a classic problem in strategy and marketing research has been linked to the question: The importance of internal versus external sources of competitive advantage and the links to business performance (Hill \& Deeds, 1996; Hitt \& Ireland, 1985; Mauri \& Michaels, 1998; Porter, 1991; Rumelt, 1991).

Although an extensive body of literature focusing on a broad range of issues pertaining to competitive advantage of the firm has been published up till now (Barney, 1991; Bharedwaj, Vanradarajan \& Fahy, 1993; Day \& Wensley, 1988), this article is based on the premise that a closer examination of the sources of competitive advantage in the context of a specific industry, ie the meat processing industry, can provide managerial insight into strategic problems and opportunities that may not be readily apparent at a more aggregate level.

The paper is organized as follows: First we focus a theoretical lens on various types of sources of competitive advantages based on three main paradigms.
Hypotheses are then developed connecting sources of advantages and their interaction with business performance. Next, the data and measurements from a study of 133 meat processors in 10 European countries are presented. Finally, we test several models of competitive advantage by means of structural equation modeling. We conclude with a discussion of our findings and implications for further study.

\section{Antecedents to competition: sources of competitive advantages}

In the strategic management literature there are at least three main paradigms for explaining sustained superior performance of the firm (Hansen \& Wernerfelt, 1989; McGrath, MacMillan \& Venkataraman, 1995; Hakansson \& Snekota, 1995). By sustained performance we mean superior marketplace performance (eg market share, customer satisfaction) and financial performance (eg return of investment, shareholder wealth creation).

The first of these paradigms, ie the resource-based view, suggests that firms are fundamentally idiosyncratic, and over time accumulate unique combinations 
of resources and skills which allow them to garner rents on the basis of "distinctive competence" (Barney, 1986 \& 1991). The second paradigm, the so-called business network approach (Ford, 1990; Hakansson \& Snekota, 1995) argues that creating and sustaining competitive advantages are embedded in business relations (buyer-seller relationships, co-operative arrangement etc.). The third paradigm for explaining superior firm performance, ie the country/industry view, draws upon the concepts of industrial organization economics and comparative advantages of nations more directly related to the firm's environment. Without going deeply into the literature on firm competition and the sources of competitive advantage, we suggest that each of the paradigms relies on three different sets of sources: Firm Specific Advantages (FSAs), Localization Specific Advantages (LSAs) and Relationships Specific Advantages (RSAs).

\subsection{The resource-based view of competition: FSAs}

In the new realities of global competition, the underlying competitive emphasis in most industries appears to have shifted from being product-market based to being more resource based (Prahalad \& Hamel, 1990). According to the resource based theory, bundles of resources, rather than industry-wide structural characteristics or the product-market combinations chosen for their deployment (eg strategic conduct), lie at the core of a firm's competitive advantage (Dierickx \& Cool, 1989; Peteraf, 1993).

The basic idea is that a firm possesses and develops resources and capabilities that make it more or less unique compared to other firms. Unique ways of combining and applying innovation resources (product development capabilities), human resources, brand label capital or functional experience (production, marketing, sales etc.) are examples of such capabilities. In particular, the non-tradeable resources and capabilities (perfect immobile) which develop and accumulate within the firm are of central concern to the resource-based theory (Dierickx \& Cool, 1989). Such capabilities in turn are normally seen as production bundles of routines of a highly tacit and social complex nature and therefore tend to defy imitation.

Whether resource selection and deployment result in enduring variation across firms will depend on factor market imperfections, defined as barriers to acquisition, imitations, and substitution of key resources or inputs (Barney, 1986 \& 1991; Amit \& Schoemaker, 1993). These barriers inhibit competitors in obtaining or duplicating critical resources and they lead to longterm differences among firms in their ability to generate rents (Dierickx \& Cool, 1989).

The group of resources and capabilities from the resource-based theory has much in common with the concepts of distinctive competence, firm specific advantages (Aharoni, 1993; Johansson, 1983), and ownership advantages (Dunning, 1993). Firm Specific Advantages (FSAs) can be defined as those specific resources and capabilities which have been developed and accumulated internally in the firm and largely take the form of the possession of distinctive skills and intangible assets, which are, at least for a period of time, exclusive or specific to the firm possessing them. Firms that possess such unique skills and assets (resources) that are scarce, intangible and nonsubstituTable will outperform their rivals. Therefore we propose, there is theoretical support for the following hypothesis:

H1: FSA-factors have a positive relationship to the competitive performance/strengths of the firm.

\subsection{The business network view of competition: RSAs}

According to the business network (interaction) approach, the firm's target environment or market context most often consists of long-lasting relationships with certain customers, suppliers and other specific counterparts, rather than with an anonymous market (Axelsson \& Easton, 1992). For example, in most industrial markets it is essential for the firm to be regarded as an attractive supplier/partner which requires trust building activities such as meeting agreed-upon quality and delivery conditions, and building social and personal bonds with customer counterparts (Anderson, Hakansson \& Johanson, 1994; Ford, 1990).

It may be argued that the FSAs of the focal company cannot really be analysed independently of the specific relationships it is a part of (Ferguson et al, 1995). In the business network view it is argued that business relationships may give access to critical resources/ capabilities outside the boundary of the firm which may in some cases be more important than resources developed internally (Hakansson \& Snehota, 1995). Since interaction in business relationships is a matter of co-ordinating activities and resources this may in turn have an influence on the business performance of the focal firm in question.

In some cases, a firm can get access to critical capabilities by tapping resources from its major 
suppliers and/or customers and vice versa. In other cases, co-ordination activities between business partners means that interdependent production, logistics, development, and administrative resources are modified and adapted in order to bring about a better match between the co-operating firms. This may imply discrete changes in products, production systems or processes. From this also follows that the resource development process in the firm contains a neverending interaction between capabilities linked to its staff and capabilities linked to the relationships with business partners often based on common understanding, trust and commitment (Axelrod, 1984; Dwyer, Schurr \& Oh, 1987).

We define Relationship Specific Advantages (RSAs) as those specific resources and capabilities which have been acquired through the firm's accumulation of the ties with other business actors most often developed over time. The RSAs are developed only if both business partners consider it profiTable or otherwise worthwhile to engage in future exchange. Evidently, there is a strategic element in the development of relationships. But no choice can be made unilaterally, since the counterpart must be continuously motivated to engage in the relationship.

Since firms co-operate in business relationships in pursuit of profitability or some other payoff linked to business performance (eg co-operation may raise joint productivity of the relationship partners), we would expect that the relationship-specific advantages have a positive impact on business performance. We hypothesize the following:

H2: RSA-factors have a positive relationship to the competitive performance/strengths of the firm.

\subsection{The country/industry view of competition: LSAs}

Firm performance is also a function of the location of firms in the industry structure and/or national environment. First, it can be argued that the FSAs are not valuable per se. The FSAs are valuable because they allow firms to perform activities that create advantages, in particular product markets (Porter, 1991; Collis \& Montgomary, 1995).

Second, an industry structure explanation may be plausible because a firm will generate different levels of performance depending on the degree of rivalry it faces for given stocks of resources and assets, which in turn depends on the location of other competitors (Cool, Dierckx \& Martens, 1994). Industrial economics (IO) largely based on the structure-conduct-perfor- mance (SCP) paradigm (Bain, 1956) emphasizes barriers to competition, and take the position that industry effects will explain differences in profitability. Consequently, the competitive value of resources can be enhanced or eliminated by changes in input prices, technology, vertical integration, buyer needs etc. which an inward focus on resources and competencies will overlook.

Whereas firm resources and capabilities are clearly something intrinsic to firms, country and industry specific factors are more directly related to the environment in a broad sense. Factors such as the national endowment of production factors (labour costs, capital costs, etc.), the level of competition, industrial organization are examples of localizational factors that can differ between firms. These have much in common with Porter's analysis of the competitive advantages of nations (Porter, 1990) and with Dunning's discussion of location-specific advantages within the theory of the MNCs (Dunning, 1988). Often they are labelled the sources of comparative advantages and are most often considered exogenous to the firm. On this background, we hypothesize the following:

H3: LSA factors have an impact on the business performance/strengths of the firm.

However, the causal relationships between the LSA factors and business performance cannot be specified in a general way since broad environmental forces from either the national level (endowments of resources, industry policy etc.) or the industry level may have a positive as well as negative impact on business performance. Firms located in high cost countries, for example, are expected to have comparative disadvantages, which in turn will have a negative impact on firm performance. On the other hand, firms with high market shares competing in monopolistic or oligopolistic market structures can expect a positive impact on profitability from their industry location.

\subsection{The combined view of competitive advantages: Interaction effects}

According to the preceding discussion we would expect that in reality it is difficult to make a sharp distinction between the internal resources and capabilities (FSAs) and external sources in terms of localization factors (LSAs) and business relationships factors (RSAs) as they reinforce each other in an interacting way. Thus, we expect significant interaction effects between the three sets of explanatory variables. In the following, 
the causality and the direction of relationships between the FSAs, LSAs, RSAs and the links to business performance are considered.

LSA-FSA links. If a company is located in an environment characterized by resource abundance (ie scarce endowment of raw materials, labour, capital etc.) it is reasonable to influence firm strategy. For example, the existence of high labour costs will increase the incentives of the firm either to exploit economies of scale in the production and distribution by process innovations, introduction of labour saving technology etc. and/or through product differentiation. Or high costs of raw materials will increase the incentives to produce low volume - high value added finish products.

Also, the nature of competition (the market structure) is expected to have an impact on the strategy of resource deployment. Or creating entry barriers through brand positioning, for instance, can diminish the threats of new entrants (Scherer, 1980). Because of the indirect links between the potentials of creating entry barriers and the investment in brand assets, the possibilities for premium pricing thus can boost income and thereby profits. These arguments suggest the following hypothesis:

H4: There is an indirect relationship from the LSA factors to the FSA factors when explaining the business performance/strengths of the firm.

LSA-RSA links. Industry factors as well as the national endowment of production factors (input prices) will also influence the RSAs. The relationship-specific advantages are, at least in part, determined by the quality of the customers, suppliers and competitors in a country or region. Inter-organizational ties, for example, may also be created and developed because of specific industry-related localizational factors, such as an attractive R\&D environment, important "change agents", industrial policy incentives etc. The host government ability to stimulate, upgrading of the local environment, through a supportive macro-economic policy and in infra-structural and educational investments, are thus important contributions to the development of relationship specific advantages. We suggest the following hypothesis:

H5: There is an indirect relationship from the LSA factors to the RSA factors when explaining the business performance/strengths of the firm.

FSA-RSA links. It seems reasonable to suggest that the RSAs partly emerge from interaction between firms, each possessing separate and different FSAs. In particular, complementary assets and skills in the interface between the business actors are expected to develop based on the relative positions of the FSAs of each partner. Also, RSAs may influence the FSAs because firms acquire contacts in order to assist the process of upgrading their resources and capabilities. Therefore, we would expect to find reciprocity between the relationships between the FSAs and the RSAs. Finally, the following hypotheses are formulated:

H6: There is an indirect relationship from FSA factors to RSA factors when explaining the business performance/strengths of the firm.

H7: There is an indirect relationship from RSAfactors to FSA factors when explaining the business performance/strengths of the firm.

The seven hypotheses are combined in the structural model as illustrated in Figure 1. The arrow numbers correspond to the number of hypotheses. The model shows that we expect direct relationships from FSAs, LSAs and RSAs to business performance (CSPs), and indirect relationships from FSAs to RSAs and from LSAs to RSAs and FSAs to business performance.

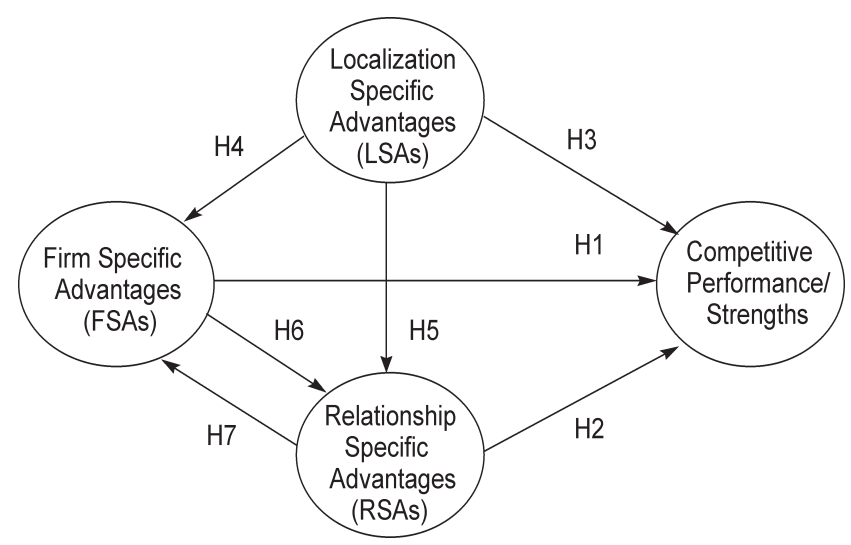

Fig 1. Structural model of relationships between Firm Specific Advantages, Localizational Specific Advantages, Relationship Specific Advantages and Business Performance

\section{Data and Measurements}

The empirical context of this study is the EU meat processing industry, which at an "industrial" level (excluding the small artisan producers) consists of approximately 2,000 to 2,500 firms. The meat processing industry covers a wide range of products derived from pork, beef and lamb. For an industry description, see GIRA (1990) and Strandskov \& Lund (1993). 


\subsection{Data}

The study is based on a postal questionnaire survey. Semi-structured interviews with industry executives were held before developing the questionnaire. Also a pre-test covering a small population of Danish meat processing firms was conducted to validate the data instrument. The survey was mailed to a sample of companies drawn from the Kompass register in ten EU countries (Denmark, Sweden, Germany, the United Kingdom, Ireland, France, Italy, Spain, the Netherlands and Belgium). To avoid small-company over-representation the sample was stratified to size including companies with more than 20 employees. The questionnaire was addressed directly to the CEO or the marketing director of the company in question.

The 1,194 cross-national questionnaire-mail-out (using two follow-up waves) produced a response rate of $15.3 \%$. This is below the average response rates in other industrial surveys (Jobber \& O'Reilly, 1998). In all, the number of usable questionnaires was 133 . Subsequently analysis of response data and a followup telephone survey of non-respondents partly confirmed that the respond database was broadly representative of the original sampling frame and, consequently, of the European meat processing industry.

The respondent set of companies in the database was characterized by the following attributes: Most of the firms were small (37\% of the total population has less than 50 employees), while the dispersion of the other firms sizes were fairly even; $75 \%$ of the meatprocessors were independent, family businesses; about half of the firms made over $50 \%$ of their total turnover through the retail sector, and most companies have an export share of less than $5 \%$ of the total turnover.

\subsection{Measures}

In order to test the hypotheses in the preceding section, several items measuring the sources of competitive advantages of the firm were developed. To specify the context of the sources of competitive advantages and the performance consequences, it was decided to apply the main product (in terms of turnover within the range of all offered processed meat products) as the unit of analysis.

FSA measures. In order to obtain an understanding of the importance of the FSA factors the companies were asked to evaluate their strengths and weaknesses. The following questions were asked "For your main product, please, on a scale ranging from much poorer to much better indicate your competitive positions vis- à-vis your main competitor(s)". The specific FSA variables were chosen from previous research and industry studies. They suggest that competition in the meat processing industry revolves around a few asset stocks (eg innovation and branding), as well as the firm's scope of operation, costs (in particular, raw material costs) and differentials (eg product differentiation) positions (Strandskov \& Lund, 1993).

The following nine FSAs were listed 1) level of process technology, 2) technological flexibility, 3) process development efforts, 4) product development efforts, 5) new product introductions, 6) product quality level, 7) service level, 8) price level, and 9) brand positioning.

LSA measures. The localization-specific advantages can be measured in many different ways. Two countrybased and two industry structure variables were included in this study. Based on prior studies of the meat sector (Strandskov \& Lund, 1993), both raw material costs and labour costs seem to have an important impact on the competitiveness of the meat processor since they most often account for between $70-80 \%$ of the total costs. Labour costs and raw material costs in the ten EU countries were obtained from another recent study on the competitiveness of the European slaughtering industry (Kristensen \& Strandskov, 1994). Data on industry factors were obtained from the same source and they include the following variables (i) number of competitors in each of the ten EU countries and (ii) degree of industry concentration measured as the top five meat-processors' shares of the total market in each country.

RSA measures. The importance of the RSAs in the meat processing industry has mostly to do with sources of competence based on relationships with the main actors in the business environment, ie suppliers and customers. In this study, a simple measure of long-term relationships to suppliers of raw materials (farmers) was used: The respondents were asked to indicate the importance of wide-ranging collaboration with suppliers for the competitiveness of the most important product (using a five-point Likert scale).

Also relationships to customers, in particular, the retailing sector is very important either due to cooperation on product development, sub-contracting (eg private labelling), etc. To measure long-term customer relationships, the respondents simply were asked to indicate the importance of co-product development and co-marketing of brands with the retail sector.

In order to verify whether the 17 items of competitive advantage can be grouped into the three different 
categories, a varimax rotated principal-component factor analysis was made to determine their underlying dimensions. Items with significant cross-loadings were eliminated. Based on factor interpretability, the scree test and an eigenvalue greater than one, a 7-factor solution accounting for $70 \%$ of the total variance was judged best. The Kaiser-Mayer-Olkin measure of sampling adequacy was low (0.55) indicating that using factor loading in the following analysis may not be a good idea. Appendix A shows these constructs with their rotated factor loadings.

From this it follows that the factor analysis only partly supports the assumption that the firm-specific properties belong to the same type of competitive advantage (internal resources and capabilities) while the others are related to the external environment (the measures of LSAs) or based on resource development with business partners (the measures of RSAs). Therefore, all the variables of competitive advantage will be included in the further analysis.

CSP measures. Three sets of competitive performance/ strengths variables were included 1) growth in turnover, 2) return on assets (ROA), and 3) relative market share. Traditionally, these have most widely been used in similar studies. However, a limitation of this study is the lack of publicly available financial data, since more than $50 \%$ of the sampled firms do not publish their economic results (typically small and medium-sized family enterprises). Therefore, selfreporting Likert-scaled measures of each firm's relative success were collected (subjective performance indicators). For each performance indicator, the respondents were asked to characterize the development of their main product in terms of sales growth, ROA, and market share within the last three years (5-point scale ranging from "very satisfactory" to "very unsatisfactory").

\section{Analysis and results}

The data set was subjected to confirmatory factor analysis and structural equation modelling using LISREL8 (Jöreskog \& Sörbom, 1993). First, the quality of the data was assessed by means of PRELIS2 for testing of multivariate normality for continuous variables. The pre-analysis (not reported) showed that most of the measures do not contain substantial skewness within the accepTable statistical limits, except for the measures of industry concentration and export intensity (both with a substantial positive skewness). However, several of the measures were subjected to kurtosis eg the level of quality, labour costs, costs of raw materials, access to cheap raw materials, industry concentration and export intensity.

Because the assumption of multivariate normality is not confirmed, and because kurtosis cannot be corrected with a simple transformation of the data, it was decided to use the Maximum Likelihood (ML) method to estimate the models. In general, ML has proved to be relative robust in the case of substantial skewness and kurtosis (Hair, Anderson, Tatham \& Black, 1992).

Second, a confirmatory factor analysis was run to approach reliability of the individual variables. The purpose of this step is to make sure that the observed variables are satisfactory representations of the theoretical constructs they are meant to measure. The measurement models along with the estimated reliabilities of the individual items are listed in Table 1. The item reliabilities are defined as the correlations between the item value and the true value.

The measurement model for the FSAs shows that process development, level of technology and new product introduction best reflect the constructs. The LSAs are almost determined by the number of competitors, degree of industry concentration and level of raw material costs. The measurement model for the RSAs only includes relationships with retailer as the most important indicator, whereas the other indicators show low item reliabilities. The item reliabilities are moderately high for most of the indicators of performance/ competitive strengths (CPSs).

Although, some of the individual item reliabilities are not high it is usually more important that the construct be measured adequately by all indicators jointly. For all the latent factors the index of composite reliabilities are moderately high (FSAs, $\rho c=0.61 ;$ LSAs, $\rho c=0.76$ and CSPs, $\rho c=0.75$ ).

Based on an evaluation of the reliability values and the $\mathrm{t}$-values of each item ( $\mathrm{\rho ii}<0.20$ ), the data analyses will only include the following seven measures of competitive advantages. FSAs: process development, level of technology and new product introductions; LSAs: raw material costs, number of competitors and degree of industry concentration, and RSAs: relationships with suppliers. All the CSP measures are included.

Finally, the predictive validity of the latent factors is assessed by means of structural equation modelling. Six models are estimated. The first model is the baseline model with direct links from the RSAs, LSAs and FSAs to business performance. Models 2 and 3 are the baseline models but with an indirect causal relationship from LSA to FSA and from LSA to RSA, respectively. 
Based on the realistic expectation that national/industry factors influence the amount and nature of both the relationship specific factors and the firm specific factors, a fourth model is suggested. Also with model 1 as the baseline model, models 5 and 6 test the interaction effects between the FSAs and the RSAs.

The results are shown in Table 2. The size of the $\chi^{2}$ indicates that no one of the models do produce a strong fit to the data. The p-values are particularly low for models 2, 3 and 4. However, the GFI and RMSEA indices are very satisfactory for all models. In general, the $\mathrm{R}^{2} \mathrm{~S}$ show that the models explain about one tenth of the variation in the dependent variable, the measures of business performance. Models 1, 5 and 6 produce the highest $R^{2}$.

Figure 2 reports the finding of model 6 which best explain the variation in business performance. All the paths connecting the indicators with the latent variables are found to have significant values. Furthermore, the direction of causality of the variables is as expected. All of the variables are highly significant with $p<0.01$.
The analysis confirmed the consistency of the latent variables. Also, to some degree the model confirmed that individually the latent variables do include connected indicators. Both the FSAs and the RSAs have a significant positive (direct) effect on the performance measure (the CSPs), while the LSAs have an insignificant direct effect. Therefore, hypotheses $\mathrm{H} 1$ and $\mathrm{H} 2$ are confirmed, while hypothesis $\mathrm{H} 3$ is not supported. Concerning the indirect effects, the coefficient estimate for the path linking RSAs to FSAs is as high as 0.32 and with a t-value of 2.90 indicating a strong significant indirect effect on performance. As a result, hypothesis $\mathrm{H} 7$ is supported while there is no support for hypotheses $\mathrm{H} 4, \mathrm{H} 5$ and $\mathrm{H} 6$.

\section{Discussion and conclusions}

This paper aims to provide a deeper understanding of the sources of competitive advantages on business performance. The study investigates the direction and

Table 1. Estimated Reliabilities of the Sources of Competitive Advantages

\begin{tabular}{|c|c|c|c|}
\hline Latent Variables & Indicators & $\begin{array}{c}\text { Completely standardized } \\
\text { loadings }\end{array}$ & Item reliabilities \\
\hline \multirow{9}{*}{$\begin{array}{l}\text { Firm } \\
\text { Specific } \\
\text { Advantages } \\
\text { (FSAs) }\end{array}$} & Product development efforts & 36 & .13 \\
\hline & Service level & .20 & .06 \\
\hline & Product quality level & .18 & .06 \\
\hline & Price level & .27 & .09 \\
\hline & Technological flexibility & .29 & .12 \\
\hline & Brand positioning & .47 & .14 \\
\hline & Proces development efforts & .50 & .41 \\
\hline & Level of process technology & .43 & .22 \\
\hline & New product introductions & .68 & .36 \\
\hline Localization & Labor costs & .49 & .03 \\
\hline Specific & Raw material costs & .07 & .43 \\
\hline Advantages & Number of competitors & .67 & .75 \\
\hline (LSAs) & $\begin{array}{l}\text { Degree of industry } \\
\text { concentration }\end{array}$ & .17 & .76 \\
\hline Relationship & Relationships with retailers & .57 & .29 \\
\hline Specific & Low costs of distribution & .22 & .05 \\
\hline Advantages & Relationships with suppliers & .21 & .10 \\
\hline (RSAs) & Access to cheap raw materials & .49 & .02 \\
\hline Competitive Strenghts/ & Return of investments (ROI) & .74 & .52 \\
\hline Performance & Sales growth & .59 & .52 \\
\hline (CSPs) & Relative market share & .60 & .51 \\
\hline
\end{tabular}


Table 2. Findings for goodness-of-fit indices for structural equation models

\begin{tabular}{|c|c|c|c|c|c|c|}
\hline Models & $\chi^{2}$ & $d f$. & $p$ & $G F I$ & RMSEA & $R^{2}$ \\
\hline $\begin{array}{l}\text { 1: Baseline model with links from } \\
R S A, L S A \text { and FSA to CSP }\end{array}$ & 47.9 & 30 & .02 & .95 & .067 & .10 \\
\hline $\begin{array}{l}\text { 2: As baseline model but with a } \\
\text { causal link from LSA to FSA }\end{array}$ & 57.1 & 31 & .003 & .92 & .070 & .081 \\
\hline $\begin{array}{l}\text { 3: Asbaseline model but with a } \\
\text { causal link from LSA to RSA }\end{array}$ & 57.1 & 31 & .003 & .92 & .070 & .081 \\
\hline $\begin{array}{l}\text { 4: As baseline model but with a } \\
\text { causal link from LSA to both RSA } \\
\text { and FSA }\end{array}$ & 57.1 & 31 & .003 & .92 & .072 & .081 \\
\hline $\begin{array}{l}\text { 5: As baseline model but with a } \\
\text { causal link from FSA to RSA }\end{array}$ & 49.1 & 31 & .02 & .93 & .067 & .10 \\
\hline $\begin{array}{l}\text { 6: As baseline model but with a } \\
\text { causal link from RSA to FSA }\end{array}$ & 50.4 & 31 & .015 & .93 & .069 & .11 \\
\hline
\end{tabular}

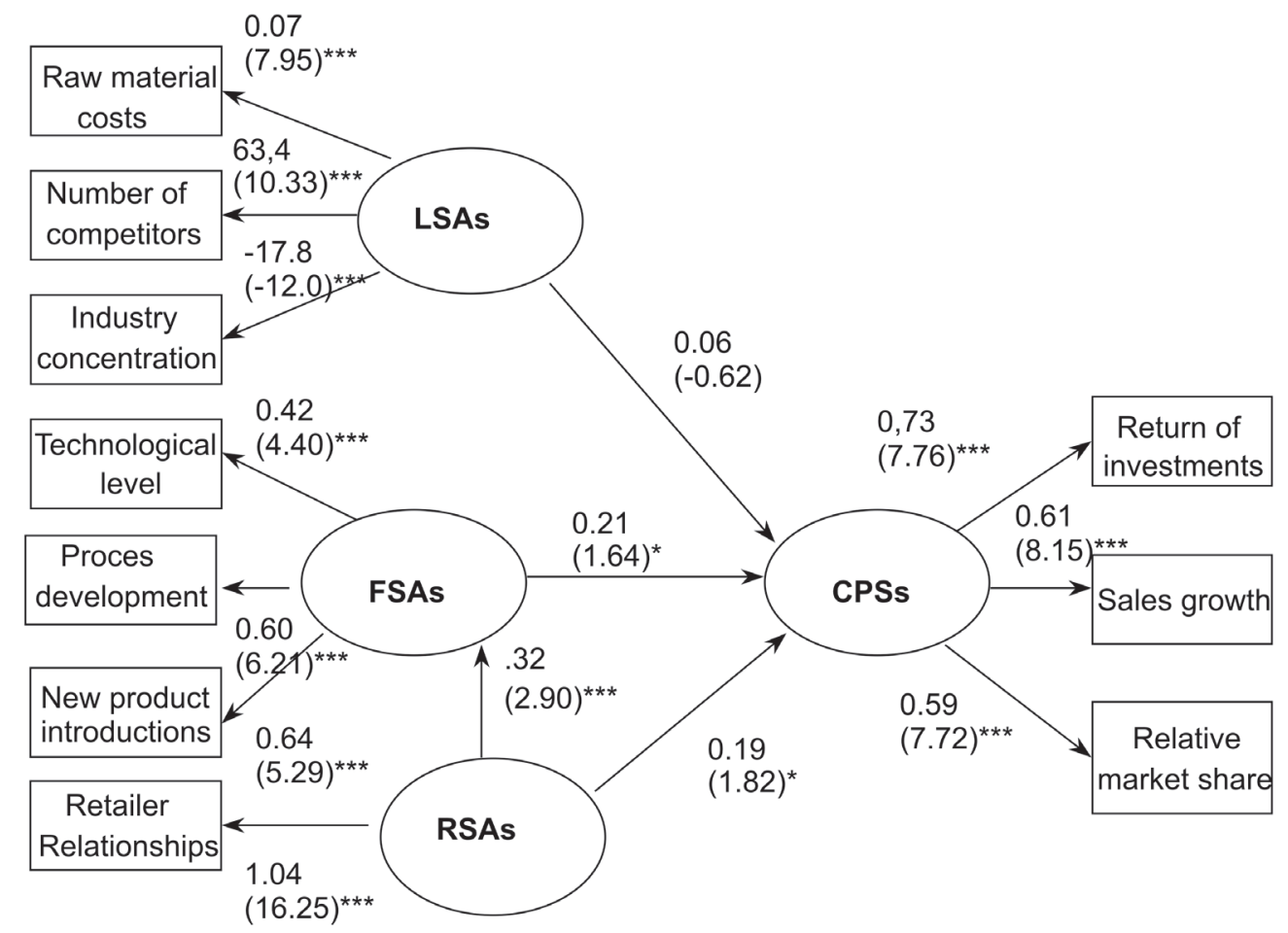

Fig 2. LISREL model of sources of competitive advantages and the links to performance: Coefficient estimates (non-standardized) and t-values (in parentheses)

causality between the different sources of competitive advantages (Firm Specific Advantages, Relationship Specific Advantages and Localization Specific Advantages) and business performance.

On the basis of data from European meat processing companies, we can tentatively conclude that the firm specific factors from the resource-based theory and relationship-specific factors from the business network theory seem to be the most important explanatory variables of business performance. However, there are also strong interaction effects between the two 
sets of factors. On the other hand, localization specific factors such as industry structure and the national endowment of resources seem to have neither a direct and/nor an indirect (significant) influence on business performance.

Of particular interest to this study is the strong (reciprocal) interplay between two sets of competitive advantages: the firm-specific and relationship-specific sources. Theoretically, feedback explanations between the firm-specific and relationship-specific variables are both logical and consistent with contemporary management research. The indirect causal links to business performance point to the conclusion that the boundary of the firm in terms of resource employment, resource developments etc. are more fluent and ambiguous than expected. Thus, the sources of firm specific advantages do not operate in isolation but are embedded and reinforced through the coordination mechanisms with business partners across the vertical value chain.

From a theoretical point this leads to the conclusion that the resource-based theory of the firm and the business network theory should be seen as complementary rather than competitive research explanations of business performance. Hence, future research should emphasize important questions concerning how the two sets of competitive advantages interact and reinforce each other. Also, further studies are needed to test the degree to which the operationalization of the firm-specific and relationship-specific measurements captures the hypothetical feedback as well as other effects. In this study, relationships with retailers were the only explanatory variable of the relationship-specific factors, which of course is a limitation. A closer examination of the nature of the relationship-specific factors is also needed. Another important finding of the study is the lack of a significant path from localization-specific factors to business performance.

For the set of industry factors in question, the lack of significance could be explained by the notion that industry structure per se may be considered as a temporary artifact of firm-specific differences in resources and skills and, as a result, performance. That is, the industry structure observed at any one point of time is an endogenous outcome of the competitive process, rather than a factor that fundamentally shapes that process (Hill and Deeds, 1996). If the notion of competition is independent of industry structure, it follows as a matter of basic logic that industry factors do not have an impact on business performance.
The analysis has at least three major strategic implications for firms operating in the meat-processing industry. First, the study clearly demonstrates that those firms developing strong ties with the food retail sector will have their business performance increased (measured by ROI, market share and sales growth) as well as have their firm-specific advantages improved by relationships with retailers. Second that investment in process and product innovations will pay off in the meat processing industry. Whether the meat processing firm should invest in process innovations rather than in product adaptation/ development are inconclusive, since the three firm specific factors account equally in explaining the variance in business performance. Third, the study indicates that factors such as the degree of industry concentration in each country, the cost of raw materials and the number of competitors seems not to influence the business performance of the meat processor's.

All these conclusions should, of course, be judged in the light of the limitations of this study and the findings must be interpreted with some caution. First, the theoretical model of the study demonstrates a simple way of relating sources of competitive advantages to business performance. As has been proposed by other researchers (see for instance Day and Wensley, 1988), the sources of advantage may only be indirectly linked to business performance by facilitating the attainment of competitive positional advantages in the form of either superior customer value and/or lower relative costs. Unfortunately, the data of this study do not include measurements of customer satisfaction, brand loyalty etc. as one of the two important dimensions of positional advantages.

Second, it is necessary to reiterate the methodological limitations. Thus, the variables of interest in the study do not account for only a modest level of variation in business performance of the firm. This is first and foremost due to the measurement model. The reliability problems potentially stem from the measurement of perceptions or stated belief in the sources of advantages and performance implications (self-typing data) rather than objective measurements or actual behavior and can therefore suffer from the well-known deficiencies of perceptual measures. These issues, along with the low response rate, constrain the strengths and generalizability of the findings. This suggests that the findings are best considered as suggestive and need further verification and testing. 


\section{References}

Hill, C. W. L. \& Deeds, D. L. (1996). The importance of industry structure for the determinants of firm profitability: A neo-Austrian perspective, Journal of Management Studies, 33(4), p. 430-451.

Hitt, M. A. \& Ireland, R. D. (1985). Corporate distinctive competence, strategy, industry and performance, Strategic Management Journal, 6, p. 273-293.

Mauri, A. J. \& Michaels, M. P. (1998). Firm and industry effects within strategic management: An empirical examination, Strategic Management Journal, 19, p. 211219.

Porter, M. E. (1991). Towards a dynamic theory of strategy, Strategic Management Journal, Winter Special Issue 12, p. 5-29.

Rumelt, R. P. (1991). How much does industry matter? Strategic Management Journal, 12, p. 167-186.

Barney, B. (1991). Firm resources and sustained competitive advantage, Journal of Management, 17, p. 99-120.

Bharadwaj, S. G., Vanradarajan, P. R. \& Fahy, J. (1993). Sustainable competitive advantage in service industries: A review. Journal of Marketing (October), p. 83-107.

Day, G. S. \& Wensley, R (1988). Assessing advantage: A framework for diagnosing competitive superiority. Journal of Marketing, 52, p. 2-20.

Hansen, G. C. \& Wernerfelt, B. (1989). Determinants of firm performance: The relative importance of economic and organizational factors, Strategic Management Journal, 10, p. 399-411.

McGrath, R. G.; MacMillan, I. C. \& Venkataraman, S. (1995). Defining and developing competence: A strategic process paradigm, Strategic Management Journal, 16, p. 251-275.

Hakansson, H. \& Snekota, I. (1995). Developing relationships in business networks. London: Routledge.

Barney, B. (1986). Strategic market factors: Expectations, luck and business strategy, Management Science, 31, p. 1231-1241.

Ford, D. (Ed.) (1990). Understanding business markets: Interaction, relationships and networks. San Diego, CA: Academic Press.

Prahalad, C. K. \& Hamel, G. (1990). The core competence of the corporation, Harvard Business Review, p. 79-91.

Dierickx, I. \& Cool, K. (1989). Asset stock accumulation and sustainability of competitive advantage, Management Science 35, p. 1504-1513.

Peteraf, M. A. (1993). The cornerstones of competitive advantage: A resource-based view, Strategic Management Journal, 14(3), p. 179-192.

Amit, R. \& Schoemaker, P. J. (1993). Strategic assets and organizational rent, Strategic Management Journal, 14(1), p. 33-46.

Aharoni, Y. (1993). In search of the unique: Can firmspecific advantages be evaluated, Journal of Management Studies, 30(1), p. 29-36.
Johansson, J. (1983). Firm specific advantages and international marketing strategy. Dalhousie Discussion Papers in International Business, No. 24.

Dunning, J. (1993). The globalization of business. The challenge of the 1990s. London: Routledge.

Axelsson, B. \& Easton, G. (Eds.) (1991). Industrial networks: A new view of reality. London: Routledge.

Anderson, J. C.; Hakansson, H. \& Johanson, J. (1994). Dyadic business relationships within a business network context, Journal of Marketing, 58 (October), 1-15.

Forsgren, M.; Hagg, I.; Hakansson, H.; Johanson, J. \& Mattsson, L-G. (1995). Firms in networks - A new perspective on competitive power. Uppsala, Studia Oeconomiae Negotiorum, 38.

Axelrod, R. (1984). The evolution of co-operation. New York, NY: Basic Books.

Dwyer, R. F.; Schurr, P. H. \& Oh, S. (1987). Developing buyer-seller relationships, Journal of Marketing, 51 (April), p. 11-27.

Collis, D. J. \& Montgomery, C. A. (1995). Competing on resources: Strategy in the 1990s. Harvard Business Review, 73(4), p. 118-129.

Cool, K.; Dierickx, I. \& Martens, R. (1994). Asset stocks, strategic groups and rivalry. In: H. Daems \& H. Thomas (Eds.), Strategic groups, strategic moves and performance, p. 221-234, London: Pergamon.

Bain, J. S. (1956). Industrial organization, New York, NY: John Wiley.

Porter, M. E. (1990). The competitive advantage of nations. New York, NY: The Free Press.

Dunning, J. (1988). The eclectic paradigm of international production: A restatement and some possible extentions, Journal of International Business Studies, 19(1), p. 1-32.

Scherer, F. M. (1980). Industrial market structure and economic performance, 2nd ed. Chicago: Rand McNally.

GIRA (1990). European meat companies. Processed meat synthesis. A multi-client study. Grilly, July.

Strandskov, J. \& Lund, E. (1993). Danske kфdforadlingsselskabers internationale konkurrenceevne (in Danish). Mimeo. Report prepared for the Danish Pork and Meat Association, Copenhagen.

Jobber, D. \& O'Reilly, D. (1998). Industrial mail surveys. A methodological update. Industrial Marketing Management, 27, p. 95-107.

Kristensen, B. \& Strandskov, J. (1994). Danske slagteriers konkurrenceevne i europaisk belysning: En konkurrentanalyse (In Danish). Research Report, Department of International Business, Aarhus School of Business (The competitiveness of the Danish slaughtering industry).

Jöreskog, K. G. \& Sörbom, D. (1993). LISREL VIII: User's reference guide. Chicago IL: Scientific International Inc.

Hair, J. F., Anderson, R. E., Tatham, R. L. \& Black, W. C. (1992). Multivariate data analysis with readings. New York, NY: Macmillan Publishing Company. 


\section{Appendix A: Factor analysis of measures}

Factor 1

Factor loadings

$\begin{array}{lr}\text { Degree of industry concentration } & -0.91 \\ \text { Number of competitors } & 0.88 \\ \text { Raw material costs } & 0.74\end{array}$

Eigenvalue $=2.63 ;$ total variance explained $=15.5 \%$

Factor 2

$\begin{array}{lr}\text { Brand positioning } & 0.79 \\ \text { Product development efforts } & 0.78 \\ \text { Labour costs } & -0.62\end{array}$

Eigenvalues $=2.54 ;$ total variance explained $=15.0 \%$

Factor 3

$\begin{array}{ll}\text { Product quality level } & 0.82\end{array}$

Price level $\quad 0.71$

Service level $\quad 0.63$

Eigenvalues $=1.83 ;$ total variance explained $=10.7 \%$

Factor 4

Process development efforts $\quad 0.72$

Level of process technology $\quad 0.70$

$\begin{array}{ll}\text { Technological flexibility } & 0.67\end{array}$

Eigen values $=1.39 ;$ total variance explained $=8.2 \%$

Factor 5

Relationships with retailers $\quad 0.84$

New product introductions $\quad 0.50$

Eigen values $=1.29 ;$ total variance explained $=7.6 \%$

Factor 6

Access to cheap raw materials

Eigen values $=1.17 ;$ total variance explained $=6.9 \%$

Factor 7

Low costs of distributions $\quad 0.76$

$\begin{array}{ll}\text { Relationships with raw material suppliers } & 0.67\end{array}$

Eigen value $=1.01 ;$ total variance explained $=6.2 \%$

Kaiser-Mayer-Olkin measure of sampling adequacy: 0.55

Bartlett's test of sphericity: $\chi^{2}=582 ; \mathrm{df}=136, \mathrm{p}=0.000$ 